\title{
Dose-dependent association of smoking and bronchial hyperresponsiveness
}

\author{
Maria Juusela', Paula Pallasaho², Eva Rönmark ${ }^{3,4}$, Seppo Sarna ${ }^{5}$, Anssi Sovijärvi ${ }^{1}$ \\ and Bo Lundbäck ${ }^{3,6}$
}

Affiliations: 'Dept of Clinical Physiology and Nuclear Medicine, HUS Medical Imaging Centre, Helsinki University Central Hospital, Helsinki, ${ }^{2}$ Control of Hypersensitivity Diseases, Finnish Institute of Occupational Health, Helsinki, and ${ }^{5}$ Dept of Public Health, Helsinki University, Helsinki, Finland. ${ }^{3}$ The OLIN Studies, Sunderby Central Hospital of Norrbotten, Luleå, ${ }^{4}$ Dept of Clinical Medicine and Public Health, Division of Environment and Occupation, Umeå University, Umeå, and ${ }^{6}$ Krefting Research Centre, Institute of Medicine, University of Gothenburg, Gothenburg, Sweden.

Correspondence: M. Juusela, Dept of Clinical Physiology and Nuclear Medicine, Helsinki University Central Hospital, Meilahti Hospitals, HUSLAB, BP 340, 00029 HUS, Finland. E-mail: maria.juuselaahelsinki.fi

ABSTRACT Our aim was to study the association of smoking habits and environmental tobacco smoke (ETS) exposure with bronchial hyperresponsiveness (BHR).

A random sample of 292 adults was examined using a structured interview, spirometry, skin prick tests, exhaled nitric oxide fraction ( $\mathrm{FeNO}$ ) and bronchial histamine challenge.

A large majority of subjects with BHR were smokers or ex-smokers. Starting to smoke before 20 years of age was significantly associated with BHR, as was current smoking, quantity of smoking and ETS exposure. The severity of BHR increased significantly with increasing pack-years of exposure $(p<0.001)$. Current smokers with decreased lung function were at a particularly high risk of BHR. Impaired forced expiratory volume in $1 \mathrm{~s}$ and mean maximal expiratory flow were independent determinants for more severe BHR, regardless of age. In multivariate analysis, smoking remained an independent determinant for BHR after adjustment for impaired lung function and other covariates: $\geqslant 15$ pack-years yielded an odds ratio of 3.00 (95\% CI 1.33-6.76) for BHR. The association between BHR and FeNO was dependent on smoking habits.

The results indicate that smoking is a significant risk factor for BHR, with a dose-dependent pattern, and that the severity of BHR increases with pack-years. The findings strongly suggest assessment of smoking habits in subjects with BHR.

@ERSpublications

Bronchial hyperresponsiveness is dose-dependently linked to smoking; severity increases with pack-years http://ow.ly/pad0H

Received: May 082012 | Accepted after revision: April 182013 | First published online: May 302013

Support statement: This part of the FinEsS study was supported by the Helsinki University Hospitals (Project TYH1235) with grants from the Ida Montin Foundation and Research Foundation for Pulmonary Diseases, Finland.

Conflict of interest: None declared.

Copyright @ERS 2013 


\section{Introduction}

Smoking causes chronic airway obstruction, which mostly develops gradually from peripheral airways towards large airways [1,2]. Large-scale international studies have shown that smoking is a risk factor for bronchial hyperresponsiveness (BHR) [3-5], but whether the quantity of smoking exposure is associated with the severity of BHR is still in question. A dose-dependent association of smoking and small airway obstruction as possible independent trigger factors for BHR severity has not been explored in detail.

There are only a few recent epidemiological studies that have assessed a large variety of possible determinants of BHR [6, 7]. The majority of epidemiological studies on BHR are descriptive and have reported their results of $\mathrm{BHR}$ as a dose-response slope or dose-response rate [8]. Translating these measures of BHR into clinical practice is laborious, thus they have been used only in research [5, 7]. BHR testing is a common tool in diagnosing asthma, but the effects of smoking have been unclear when interpreting causes of BHR [9]. The association of BHR and smoking has been studied mostly in selected populations [10-12].

We aimed to study the effects of smoking, environmental tobaccos smoke (ETS) exposure and exhaled nitric oxide fraction $(\mathrm{FeNO})$ on BHR in adult subjects representing the general population in Helsinki, the capital of Finland. Bronchial responsiveness was assessed by a dosimetric method with histamine [13], which has been in clinical use for over three decades in Finland. The effect of the quantity of smoking exposure on BHR severity, defined by a provocative dose of histamine inducing a $15 \%$ decrement in forced expiratory volume in $1 \mathrm{~s}$ (FEV1) in two clinically validated cut-off levels (PD15 $1.6 \mathrm{mg}$ and $0.4 \mathrm{mg}$ [13]), was calculated by multiple regression analysis. When calculating the effects of current smoking status, pack-years and ETS on $\mathrm{BHR}$, variables of ventilatory function and of small airway obstruction were used as co-variates.

\section{Subjects and methods}

Study cohort

The study sample consisted of 292 randomly selected subjects, who had taken part in a postal questionnaire survey in Helsinki in 1996 [14]. The population of the FinEsS I postal survey $(n=8000)$ was randomly selected from the Finnish population register and designed to correspond to the general population with respect to age and sex. The participation rate of the FinEsS I study was $76 \%(n=6062)$. Of the participants, 1200 were randomly invited to participate in the FinEsS II clinical study, and half of those $(n=600)$ were randomly selected to take part in this BHR study. The participation rate for the FinEsS II clinical study was $54 \%(n=643)[15]$ and for the BHR study $45.4 \%(n=292)$.

This BHR study sample represents well the original study cohort from 1996 in terms of age, sex and prevalence of asthma, respiratory symptoms, and smoking habits [15]. The age range was 26-66 years (mean 47 years) and 58\% were female. The baseline FEV1 of the studied subjects ranged from $60 \%$ to $136 \%$ of predicted Finnish reference values [16]. The Helsinki University Central Hospital ethics committee approved the study, and all subjects gave signed informed consent. Demographic data are presented in tables 1 and 2.

\section{Clinical examinations}

BHR challenge tests were carried out within 2 weeks of an initial clinical visit including a structured interview, spirometry with bronchodilation test and skin prick tests (SPTs) [17]. The interview was performed by a physician, and a trained nurse performed the spirometry and the SPTs. SPTs were performed in subjects aged $<61$ years with two controls (positive control: histamine $10 \mathrm{mg} \cdot \mathrm{mL}^{-1}$; negative control: glycerine solvent) and 15 allergens [15]. The interview consisted of questions about respiratory symptoms, family history of asthma and allergy, living conditions, occupation, smoking habits, and ETS exposure.

\section{BHR test}

Inclusion criteria for the BHR test were a pre-test FEV1 value of $\geqslant 60 \%$ predicted or $\geqslant 1.5 \mathrm{~L}$, no respiratory infection within 4 weeks prior to testing, no marked heart diseases (myocardial infarction within 3 months, unstable coronary disease, dysfunction or arrhythmia) and no stroke. Subjects were allowed to use their regular medication, except $\beta_{2}$-agonists and antihistamines (no short-acting $\beta$-agonists for $12 \mathrm{~h}$ or longacting $\beta$-agonists for $48 \mathrm{~h}$ and no antihistamines for 5 days before testing). 18 subjects were excluded because of low baseline FEV1.

The bronchial challenge was conducted with histamine by a dosimetric method with controlled tidal breathing by using the Spira Electro 2 jet nebuliser (Spira Respiratory Care Center Ltd, Hämeenlinna, Finland) [13]. Subjects inhaled buffered histamine diphosphate aerosol in four-fold increasing doses. The end-point was a fall of $\geqslant 15 \%$ in FEV1 or used maximum noncumulative dose of histamine of $1.6 \mathrm{mg}$. After the histamine challenge, post-bronchodilation $(0.4 \mathrm{mg}$ salbutamol (Ventoline, GlaxoSmithKline, Brentford, 
TABLE 1 Demographic data of the subjects studied

\begin{tabular}{|c|c|c|c|}
\hline & Male & Female & Total \\
\hline Subjects & 123 & 169 & 292 \\
\hline Age years & $45.2 \pm 9.5(28-65)$ & $47.3 \pm 10.6(26-66)$ & $46.4 \pm 10.2(26-66)$ \\
\hline $\begin{array}{l}\text { Weight kg } \\
\text { Spirometry }\end{array}$ & $80.0 \pm 12.6(43-110)$ & $70.6 \pm 13.8(48-105)$ & $75.6 \pm 14.0(43-110)$ \\
\hline FEV1 L & $4.06 \pm 0.70(2.35-5.90)$ & $2.87 \pm 0.51(1.71-4.50)$ & $3.37 \pm 0.84(1.71-5.90)$ \\
\hline FVC\# \% pred & $99 \pm 11(67-127)$ & $99 \pm 12(72-145)$ & $99 \pm 12(67-145)$ \\
\hline FEV $1 / F V C \%$ & $77 \pm 6$ & $78 \pm 6$ & $78 \pm 6$ \\
\hline FEV1/FVC $\#$ \% pred & $95 \pm 7(\overline{71}-113)$ & $95 \pm 6(\overline{80}-115)$ & $95 \pm 7(\overline{71}-115)$ \\
\hline MEF50 L. $\mathrm{S}^{-1}$ & $4.43 \pm 1.33(1.40-8.11)$ & $3.37 \pm 0.98(1.41-6.33)$ & $3.82 \pm 1.26(1.40-8.11)$ \\
\hline MEF50\# \% pred & $82 \pm 24(30-147)$ & $77 \pm 20(39-137)$ & $79 \pm 22(30-147)$ \\
\hline \multicolumn{4}{|l|}{ Smoking } \\
\hline Smokers & $46(37.4)$ & $50(29.6)$ & $96(32.9)$ \\
\hline \multicolumn{4}{|l|}{ ETS } \\
\hline Ever & 84 (68.3) & $131(77.5)$ & $215(73.6)$ \\
\hline Both at work and at home & 49 (39.8) & 65 (38.5) & $114(39.0)$ \\
\hline Inhaled corticosteroids ${ }^{+}$ & $3(2.4)$ & $6(3.6)$ & $9(3.1)$ \\
\hline
\end{tabular}

Data are presented as $\mathrm{n}$, mean \pm SD (range) or $\mathrm{n}(\%)$. Predicted values according to VILJANEN et al. [16]. FEV1: forced expiratory volume in $1 \mathrm{~s} ; \%$ pred: $\%$ predicted; FVC: forced vital capacity; MEF50: maximal expiratory flow at $50 \%$ of FVC; ETS: environmental tobacco smoke. ${ }^{\#}$ : lung function values, $\mathrm{n}=291 ;{ }^{\natural}$ : at work and/or at home; ${ }^{+}$: daily use of inhaled corticosteroids $\geqslant 200 \mu \mathrm{g}$.

TABLE 2 Smoking as a risk factor for bronchial hyperresponsiveness (BHR) in terms of odds ratios, univariate analysis

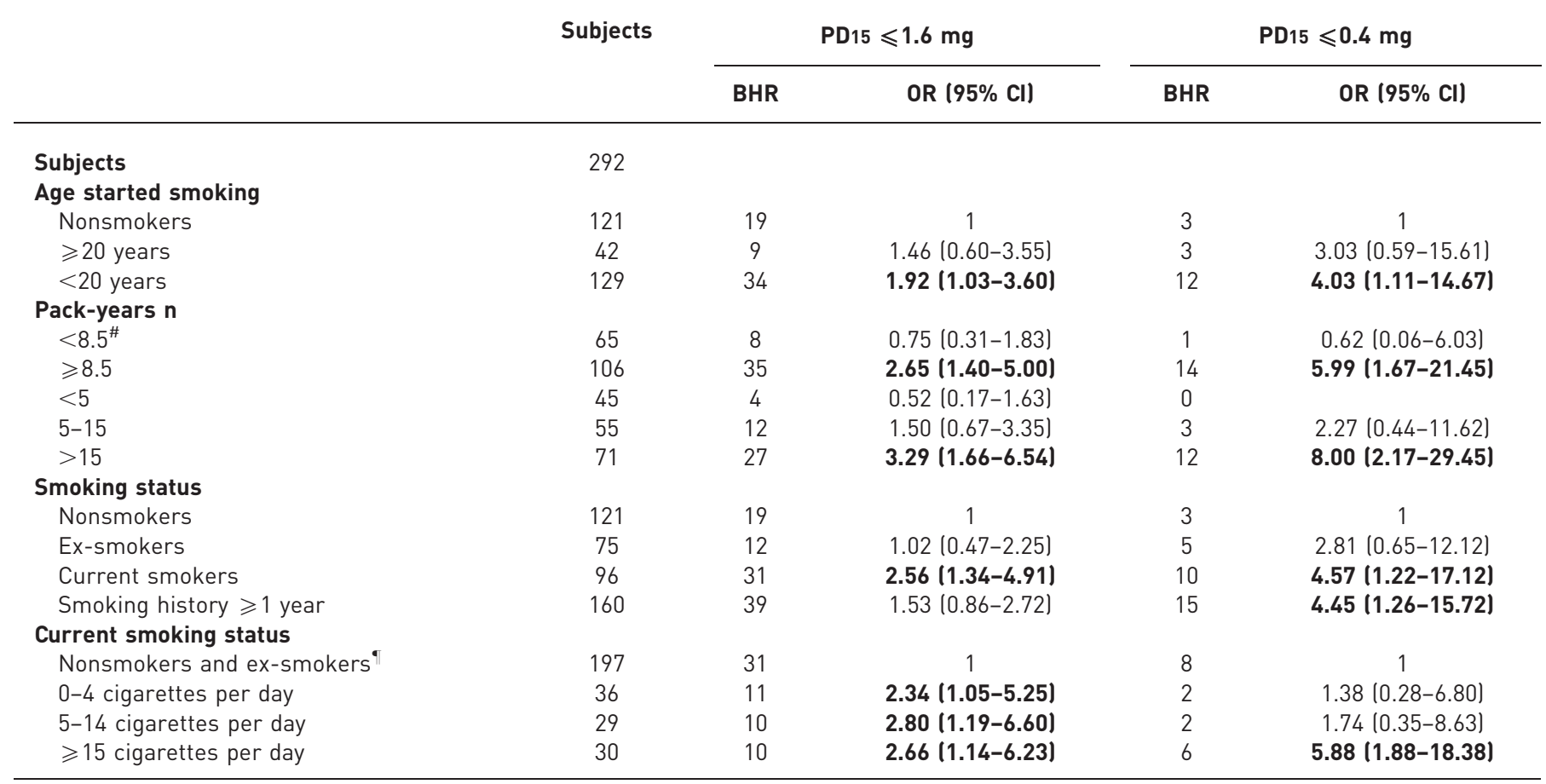

Data are presented as $\mathrm{n}$, unless otherwise stated. PD15: provocative dose causing a $15 \%$ fall in forced expiratory volume in $1 \mathrm{~s} .{ }^{\#}$ : mean of packyears in the whole cohort, $8.5{ }^{\circ}{ }^{\natural}$ : nonsmokers and ex-smokers, and one missing included ( $\left.\mathrm{n}=197\right)$. Bold type represents statistical significance. 
UK) via Volumatic ${ }^{\circledR}$ (GlaxoSmithKline, London, UK)) FEV1 was measured. PD15 was calculated by interpolation [18].

Within 2 weeks prior to the bronchial challenge tests, flow-volume spirometry was performed using a Vmax22 Spirometer (SensorMedics, Yorba Linda, CA, USA), according to the 1994 criteria of American Thoracic Society (ATS) [19]. We recorded the largest FEV1 and forced vital capacity (FVC) from at least three acceptable curves, and the flow parameters, such as the mean maximal expiratory flow at 50\% of FVC (MEF50), were obtained from the curve with the biggest sum of FEV1 and FVC. Bronchodilation response was measured after the histamine test. A nose clip was used at all spirometric examinations. In 95\% of the subjects, the FeNO was measured at the $50 \mathrm{~mL} \cdot \mathrm{s}^{-1}$ flow rate according to the 1999 ATS criteria [20]. The FeNO measurements were performed before the BHR testing.

\section{Definitions}

The definitions used in the present study are presented in table 3.

\section{Statistical analyses}

BHR severity, risk factors and symptoms associated with BHR were determined at two different cut-off levels of PD15. Risk factors for BHR were calculated by multiple logistic regression analysis, which included as independent variables age, sex, family history of asthma and determinants that were significant in the univariate analysis. For the analysis, the mean values of age (47 years) and pack-years (8.5) were used. The results are expressed as odds ratios (95\% CI). Chi-squared and Fisher's exact tests were used to assess differences between groups. Furthermore, $\mathrm{p}<0.05$ was considered statistically significant. The analyses were repeated for individuals $<45$ years and $\geqslant 45$ years of age to define the effects of smoking exposure as a potential inception for BHR measured in the two age groups.

Statistical Package for Social Sciences (SPSS version 15.0 for Windows; IBM, Chicago, IL, USA) and StatXact 8_2007 (Cytel Inc., Cambridge, MA, USA) were used for the statistical analysis.

\section{TABLE 3 Definitions}

BHR
Marked BHR
BHR severity [13]
Severe
Moderate
Mild
None
Normal FEV1
Normal FVC
Normal FEV1/FVC
Normal MEF50
Physician-diagnosed asthma

Childhood wheeze

\section{Atopy}

Nonsmoker

Ex-smoker

Exposure to ETS

$$
\begin{aligned}
& \text { Histamine PD15 } \leqslant 1.6 \mathrm{mg} \\
& \text { Histamine PD15 } \leqslant 0.4 \mathrm{mg} \\
& \text { PD15 } \leqslant 0.100 \mathrm{mg} \\
& \text { PD15 } 0.101-\leqslant 0.400 \mathrm{mg} \\
& \text { PD15 } 0.401-\leqslant 1.600 \mathrm{mg} \\
& \text { PD15 } \geqslant 1.601 \mathrm{mg} \\
& \geqslant 80 \% \text { pred } \\
& \geqslant 80 \% \text { pred } \\
& \geqslant 88 \% \text { pred } \\
& \geqslant 63 \% \text { pred }
\end{aligned}
$$

Subjects who answered "yes" to the question: "Have you been diagnosed as having asthma by a physician?"

Subjects who answered "yes" to the question: "Have you been diagnosed as having asthma or have you had wheeze in childhood?"

At least one positive skin prick test reaction to any of the tested allergens or reported symptoms of allergic rhinoconjunctivitis Never-smoker or smoking $<4$ cigarettes per month

Those who had quit smoking $\geqslant 12$ months prior to the study The subjects were asked three separate questions about ETS: "Have you ever been exposed to environmental tobacco smoke at home/at work/ generally in the surroundings?" The answer alternatives of all three questions were: "never", "yes previously, not any more" and "yes, currently"

ETS at home or at work, or both, currently or previously ETS currently at the time of the study at home, at work, or both

\section{ETS exposure ever} ETS exposure present
BHR: bronchial hyperresponsiveness; FEV1: forced expiratory volume in $1 \mathrm{~s}$; FVC: forced vital capacity; MEF50: maximal expiratory flow at 50\% of FVC [21]; ETS: environmental tobacco smoke; PD15: provocative dose of histamine inducing a $15 \%$ fall in FEV1; \% pred: \% predicted. 
FIGURE 1 Association of the severity of bronchial hyperresponsiveness (BHR) and history of smoking (pack-years). BHR is classified according to the provocative dose of histamine inducing a $15 \%$ fall in forced expiratory volume in $1 \mathrm{~s}$ (PD15) [13] as: no BHR (>1.6 mg), mild (0.401-1.6 mg), moderate $(0.101-0.4 \mathrm{mg})$ and severe $(\leqslant 0.1 \mathrm{mg})$ in an adult general population sample of Helsinki $(n=292)$. p-value represents test for trend. ${ }^{* *}: \mathrm{p}<0.001$.

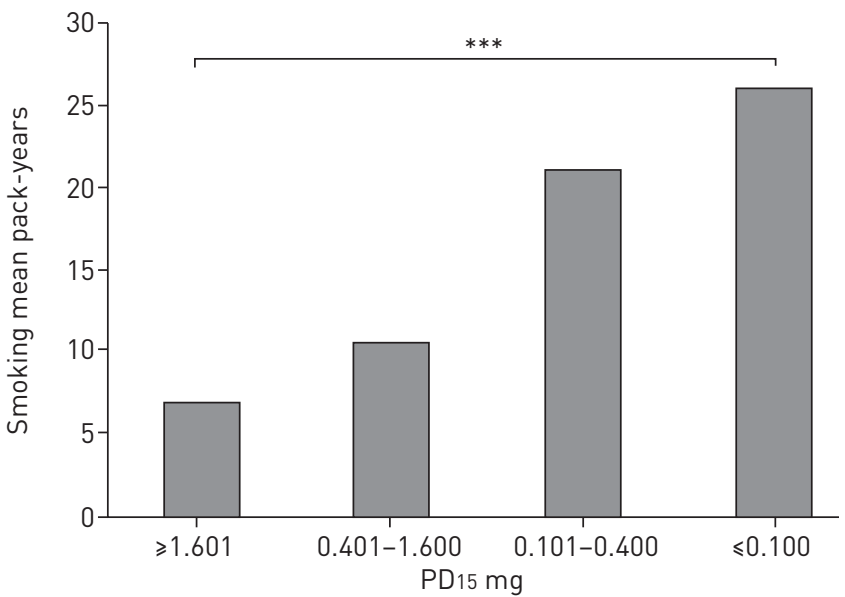

\section{Results}

Smoking

Smoking increased the risk of BHR (table 2). BHR severity increased parallel to increasing number of packyears $(\mathrm{p}<0.001)$ (fig. 1). Of the subjects with marked BHR, 56\% were smokers and $28 \%$ ex-smokers versus $28 \%$ smokers and $27 \%$ ex-smokers among the subjects without BHR. Start of smoking before the age of 20 years $(n=129)$ yielded an odds ratio of 4.03 (95\% CI 1.11-14.67) for marked BHR and the corresponding values for a start of smoking before 15 years was 5.38 (95\% CI 1.14-25.37), with nonsmokers as reference. No one who had started smoking after the age of 26 years had marked BHR.

The association of pack-years with BHR and marked BHR became significant at only 1+ pack-year (OR 1.91, 95\% CI 1.05-3.49 and OR 4.07, 95\% CI 1.15-14.39, respectively). A smoking history of $\geqslant 8.5$ packyears yielded an odds ratio of 2.65 (95\% CI 1.40-5.00) for BHR and 5.99 (95\% CI 1.67-21.45) for marked BHR. Having a smoking history of $>15$ pack-years resulted in an odds ratio of 8.00 (95\% CI 2.17-29.45) for marked BHR, and, combined with obstruction, in values of 12.85 (95\% CI 3.36-49.09). Current smokers with impaired ventilatory function defined as FEV $1<80 \%$ pred, FEV1/FVC $<0.7$ and MEF50 $<63 \%$ pred, were all at a high risk for BHR (OR 10.17, 8.37 and 6.85, respectively) (table 4).

In the multivariate analysis, smoking remained as an independent determinant of BHR and marked BHR when co-variates, including impaired lung function and other determinants of BHR that were significant in the univariate analysis, were taken into account (table 5). Smoking $>15$ pack-years remained significantly associated with both BHR and marked BHR after adjustment for age, female sex, wheezing or asthma in childhood, FEV $1<80 \%$ pred and MEF50 $<63 \%$ pred (table 4 ). Besides ventilatory function variables, asthma or wheeze during childhood also remained as significant risk factors for BHR in the multivariate analysis.

\section{Environmental tobacco smoke}

Of the subjects with marked BHR, 33\% reported ETS exposure at the time of the study versus $17 \%$ among those not having BHR. ETS at home and at work were associated with marked BHR (OR 3.73, 95\% CI 1.05-13.17 and OR 4.65, 95\% CI 1.32-16.42, respectively). However, exposure to tobacco smoke in nonsmokers only was not significantly associated with BHR.

\section{Ventilatory function}

Low baseline FEV1 values correlated with low PD15 values $(\mathrm{p}<0.001)$.

Baseline FEV1 $<80 \%$ pred together with obstruction (FEV1/FVC $<0.7$ ) increased the risk of BHR, yielding an odds ratio of 5.73 (95\% CI 1.75-18.73) (table 4). In univariate analysis of lung function variables, MEF50 below the lower limit of normal (LLN) appeared as a strong determinant for BHR and marked BHR. When MEF50 < LLN was the only sign of decreased ventilatory function, it was significantly associated with BHR (OR 2.65, 95\% CI 1.21-5.82).

\section{FeNO in relation to BHR}

The association between FeNO and BHR was strongly dependent on smoking habits (fig. 2). In nonsmokers with BHR, FeNO was $>25 \mathrm{ppb}$ and significantly higher compared to the remaining subjects $(\mathrm{p}=0.008)$. 
TABLE 4 Lung function, smoking, and risks for PD15 $\leqslant 1.6 \mathrm{mg}$ and PD15 $\leqslant 0.4 \mathrm{mg}$, analysed by univariate and multivariate analysis

Independent variables
Subjects

Dependent variables

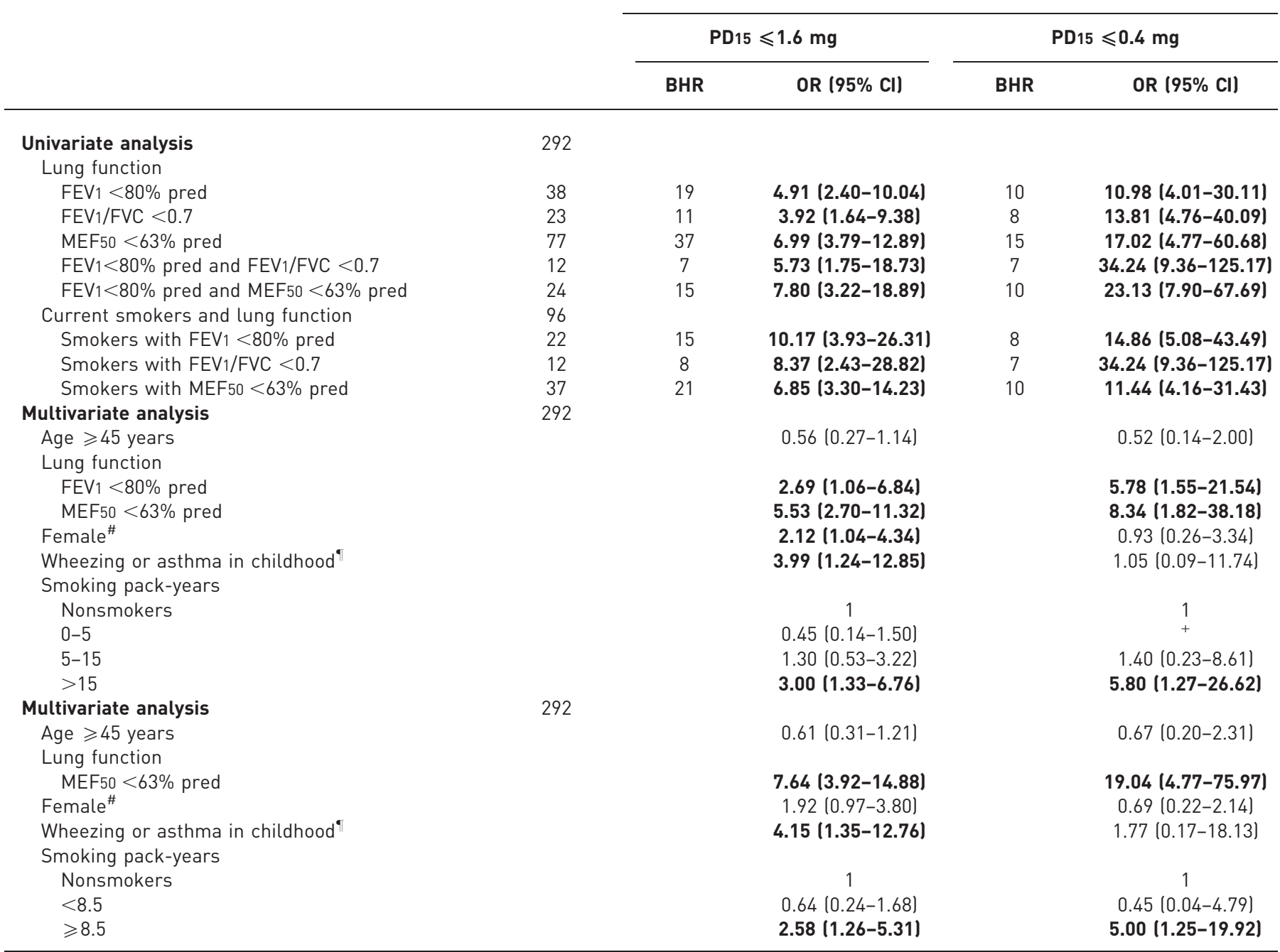

Data are presented as $\mathrm{n}$, unless otherwise stated. PD15: provocative dose of histamine inducing a $15 \%$ fall in forced expiratory volume in $1 \mathrm{~s}$ (FEV1); BHR: bronchial hyperresponsiveness; \% pred: \% predicted; FVC: forced vital capacity; MEF50: maximal expiratory flow at 50\% of FVC [21]. \#: males as reference group; ": "no" as reference group; ${ }^{+}: \mathrm{n}=0$.

Current exposure to ETS was associated with a lower FeNO (13.2 ppb) compared to nonexposed subjects $(19.3 \mathrm{ppb})(\mathrm{p}=0.002)$.

Influence of age

The association of smoking with BHR was examined in two age groups: those $<45$ years of age (group 1: mean age 36 years; $n=126$ ) and those $\geqslant 45$ years of age (group 2 : mean age 54 years; $n=166$ ). The prevalence of BHR did not differ between groups 1 and 2 (19.8\% versus $22.3 \%$, respectively), whereas marked BHR was more common in group 2 (4.8\% versus $7.2 \%)$. Group 1 included more nonsmokers ( $46.8 \%$ versus $37.3 \%$ ) and the number of pack-years was lower than in group 2 (mean 5.6 versus 10.8). The proportion of subjects having obstruction defined as FEV1/FVC $<88 \%$ pred was the same in groups 1 and 2 ( $30.4 \%$ versus $30.1 \%$, respectively) but obstruction defined as FEV1/FVC $<0.7$ was more common in group 2 ( $1.6 \%$ versus $12.0 \%$ for groups 1 and 2 , respectively).

In group 1, smoking and LLN of FEV1 were not significantly associated with BHR (OR 1.78, 95\% CI 0.68-4.46 and OR 1.93, 95\% CI 0.54-6.86, respectively), but both these factors increased the risk for BHR in group 2 
TABLE 5 Risk for PD15 $\leqslant 1.6 \mathrm{mg}$ and PD15 $\leqslant 0.4 \mathrm{mg}$, analysed by multivariate analysis

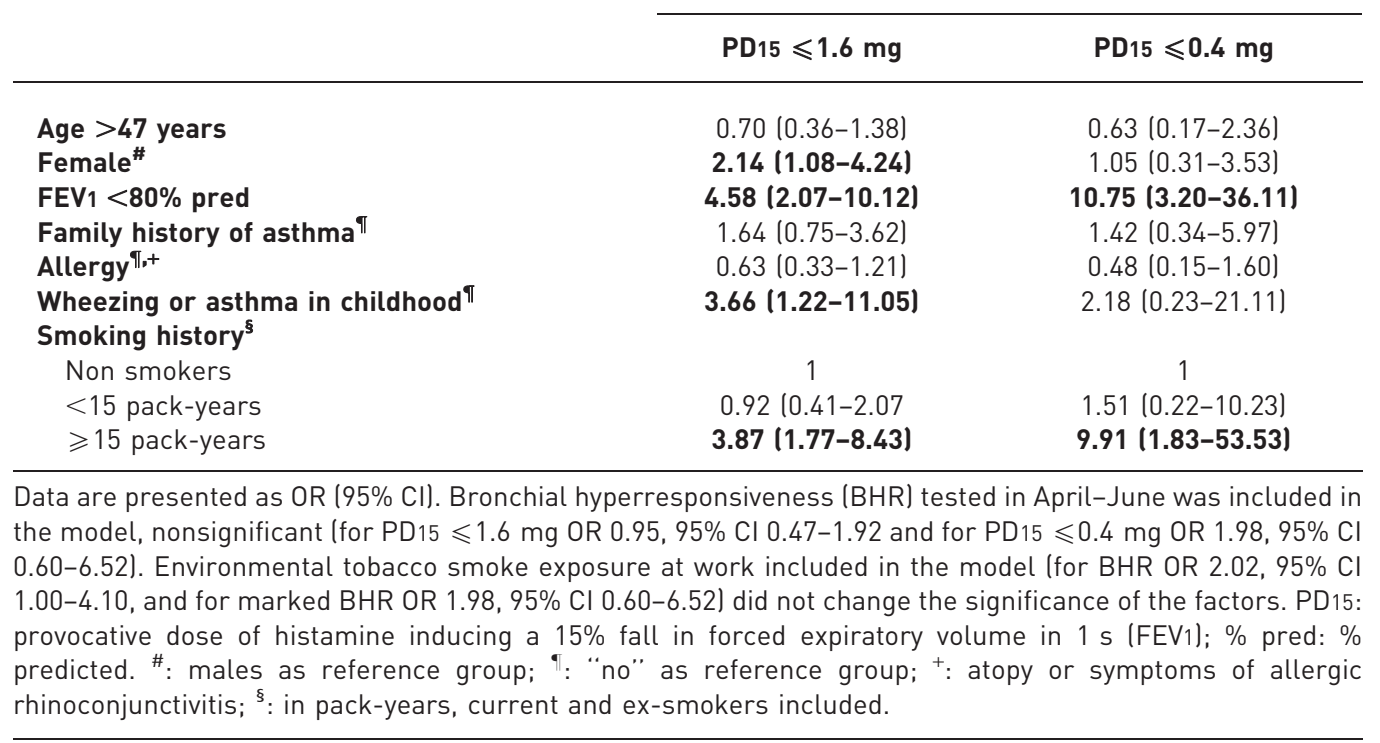

(OR 3.55, 95\% CI 1.42-8.91 and OR 11.10, 95\% CI 3.84-32.10, respectively). In the multivariate analyses, ageadjusted determinants for BHR did not differ from analyses performed without age in the models (tables 4 and 5). Of the lung function parameters, MEF50 $<63 \%$ pred increased the risk regardless of age: in group 1, when sex, wheezing or asthma in childhood and smoking (pack-years) were included in the multivariate model, odds ratios for BHR and marked BHR were 3.39 (95\% CI 1.20-9.55) and 13.60 (95\% CI 1.88-98.23), respectively.

\section{Discussion}

In this study, we found a dose-dependent association of smoking and the severity of BHR in an adult sample of the general population. The present study indicates that increasing smoking exposure, defined by pack-years, is associated with more severe BHR. The association remained significant even after adjustment of effects on BHR of decreased lung function (FEV1), airway obstruction and peripheral airflow limitation at baseline. In the multivariate model, a history of asthma or wheezing in childhood and female sex were also independent determinants of BHR.

FIGURE 2 Smoking categories with mean exhaled nitric oxide fraction (FeNO) by severity groups of bronchial hyperresponsiveness (BHR) [13] (none (provocative dose causing a $15 \%$ fall in forced expiratory volume in $1 \mathrm{~s}(\mathrm{PD} 15) \geqslant 1.601 \mathrm{mg})$, mild (PD15 0.401-1.600 mg) and marked (PD15 $\leqslant 0.400 \mathrm{mg}$ ) ) in an adult general population sample of Helsinki, Finland. Nonsmokers: mean FeNO 20.8 ppb; exsmokers: mean FeNO 18.3 ppb; smokers: mean FeNO $14.6 \mathrm{ppb}$. n=292. p-values express test for trend. Mean \pm SD FeNO is $18.1 \pm 13.47 \mathrm{ppb}$ (range 2.13-95.60 ppb). $\mathrm{p}=0.004$.

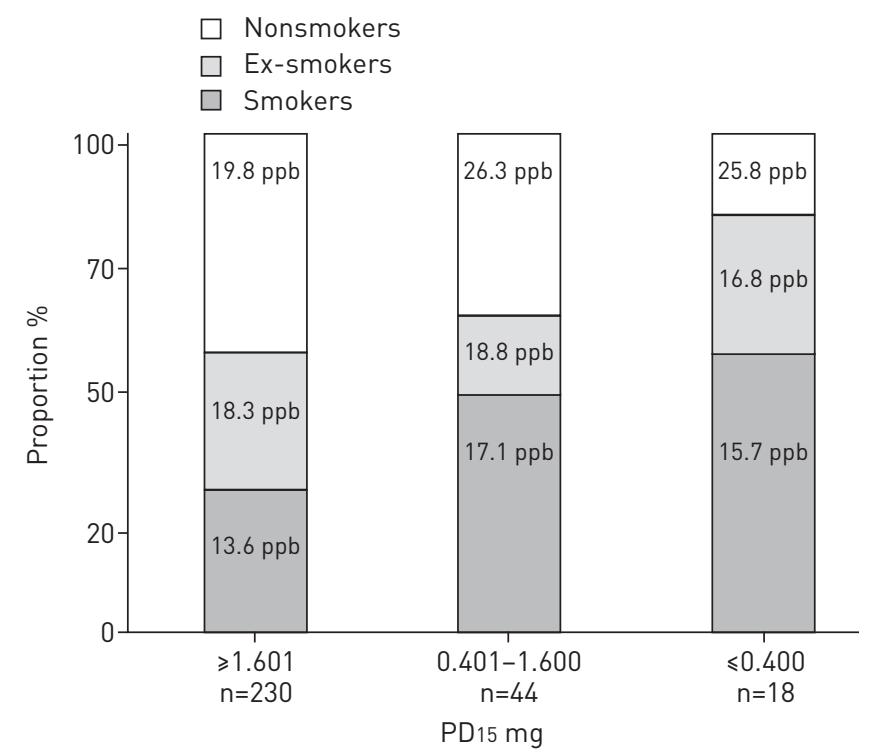


Generally, the risk factors were most strongly associated among subjects aged $\geqslant 45$ years, whereas in subjects aged $<45$ years significant associations with BHR were diluted, except for MEF50 $<63 \%$ pred.

We found that the majority of the current smokers had started to smoke at the age of 15-19 years. Starting to smoke at age 7-20 years doubled the risk of having BHR and increased the risk for marked BHR fourfold. Starting to smoke very early in life, at age 7-14 years, increased the risk for marked BHR in adulthood more than five-fold. Categorisation of smoking exposure by pack-years revealed more significant associations than the use of general terms of current smoking status, i.e. nonsmokers, ex-smokers or current smokers. Acute effects of exposure to tobacco smoke were not studied.

Our results indicate that ETS exposure and smoking interfere with FeNO values in detecting airway inflammation in a general population, similar to the results recently found by NADIF et al. [22]. Smoking exposure plays an inestimable role in evaluating the FeNO levels of an individual, thus probably explaining some of the contradictory results found in former studies of the associations of BHR with other measurements of airway regulation and inflammation $[23,24]$. Biological measurements of exposure to tobacco smoke were not performed, which results in a somewhat incomplete quantification of ETS exposure.

The inclusion criteria for participation in a study of BHR have an impact on the final outcomes. In this general population cohort, the prevalence of BHR was $21 \%$, and patients with severe or moderate BHR constituted $6 \%$ of those studied [17], the latter result fairly consistent with current data on prevalence of asthma among adults in Finland [14, 15].

However, in our study, as in all BHR studies, several of the most severe patients were excluded because of their low baseline FEV1 value. Thus, their severely decreased ventilatory function cannot be taken into account when calculating the risk factors or determinants of increased BHR. The hypothesis of the effect of the size of the airway calibre, and sex differences, are both important determinants of BHR [25], as shown in the multivariate model presented. The methodological considerations of BHR testing and comparison of the results in epidemiological studies lack this part of critical evaluation [26]. In a majority of the BHR studies, only predicted values of lung function are used in the evaluation of risk factors. This might exclude the eventual effect of decreased ventilatory reserves on BHR, particularly among elderly subjects.

As a surrogate variable of peripheral airway obstruction, we used the MEF50 from the baseline spirometry to investigate the role of flow limitation typical of a history of smoking. The repeatability and reliability of the measure is known to be lower and less precise than that of FEV1 [27]. However in our study cohort, the quality and representativeness of the spirometric measurements have been evaluated [28], and the mean FEV1 and FVC of predicted values in the present study sample conformed well to current Finnish reference values.

We found that impaired MEF50 was strongly associated with BHR. In addition, smoking $>15$ pack-years as an independent risk factor for BHR remained stable after adjustment for both MEF50 and FEV1 $<$ LLN in the multivariate model. As a sign for early airway closure, MEF50<LLN independently associated with an increased risk for BHR and marked BHR to the same magnitude as a decreased FEV1 value. Results from other studies, also assessed in general adult population samples, report a close association of decreased FEV1 and increased BHR $[3,29,30]$, but, to our knowledge, the associations of MEF50 and BHR with histamine in adult general populations have not previously been published.

Results of the analysis in individuals aged $<45$ years and $\geqslant 45$ years suggested that exposure to tobacco smoke is a potential inception for BHR after middle age. Pathologically defined BHR appears after lifelong exposures, such as tobacco smoke exposure. This is in line with the results gained from larger epidemiological BHR studies, in which remodelling changes caused by tobacco have been suggested to cause the increased BHR in a longitudinal setting [7]. As reported by VAN DEN BERGE et al. [12], the critical role of inflammatory cells, such as neutrophils, macrophages and lymphocytes, and air trapping in relation to BHR serves as a characterisation tool in the distinction of phenotypes of chronic airway diseases. Prospective studies have shown significant reduction in BHR in asthmatic smokers after quitting; thus smokers should be assisted in quitting $[10,11]$.

Limitations of the present general population study are obvious due to the small sample size of slightly less than 300 subjects. However, we could show similar associations of BHR and smoking as presented in studies among selected patient populations, such as asthmatics, subjects with allergy and with chronic obstructive pulmonary disease [10-12, 31].

The present study was performed before 2006, when smoking was banned in public places and restaurants in Finland. Along with the public ban of smoking, smoking habits have started to decrease in Finland [32]. A decrease in the prevalence of respiratory symptoms and lung function disturbances may be a consequence of the decrease in smoking, as found in prospective studies in asthmatic smokers after quitting $[10,11,31,33]$. 
In conclusion, smoking and BHR were dose-dependently associated even after correction for effects of impaired lung function, female sex and a history of asthma or wheezing during childhood. The severity of BHR increased with increasing number of pack-years, and starting to smoke before 20 years yielded a greater risk of over four-fold for marked BHR, thus indicating that smoking exposure is a trigger factor for $\mathrm{BHR}$ in middle age and older. Low MEF50, as a single spirometric measure, presented the highest odds ratio for BHR, indicating a significant association of impaired airflow limitation with BHR. Smoking and ETS exposure confounded the association of FeNO and BHR. Our results support antismoking actions and legislative restrictions of ETS exposure both at work and at home. Assessment of smoking habits in subjects with BHR is important.

\section{Acknowledgements}

Special thanks to assistants in research K. Ahlskog and M. Veneranta, to I. Sippo-Tujunen for advice and support on technical issues, the staff of the Laboratory of Lung Function and Clinical Physiology, and the staff of the Research Centre for Lung Diseases in Meilahti Hospital at Helsinki University Hospitals.

\section{References}

Barnes PJ. Immunology of asthma and chronic obstructive pulmonary disease. Nat Rev Immunol 2008; 8: 183-192.

2 Siddiqui S, Hollins F, Saha S, et al. Inflammatory cell microlocalisation and airway dysfunction: cause and effect? Eur Respir J 2007; 30: 1043-1056.

3 Schwartz J, Schindler C, Zemp E, et al. Predictors of methacholine responsiveness in a general population. Chest 2002; 122: 812-820.

4 Chinn S, Jarvis D, Luczynska CM, et al. An increase in bronchial responsiveness is associated with continuing or restarting smoking. Am J Respir Crit Care Med 2005; 172: 956-961.

5 Janson C, Chinn S, Jarvis D, et al. Effects of passive smoking on respiratory symptoms, bronchial responsiveness, lung function, and total serum IgE in the European Community Respiratory Health Survey: a cross-sectional study. Lancet 2001; 358: 2103-2109.

6 Brutsche M, Downs S, Schindler C, et al. Bronchial hyperresponsiveness and the development of asthma and COPD in asymptomatic individuals: SAPALDIA Cohort Study. Thorax 2006; 61: 671-677.

7 Curjuric I, Zemp E, Dratva J, et al. Determinants of change in airway reactivity over 11 years in the SAPALDIA population study. Eur Respir J 2011; 37: 492-500.

8 Chinn S, Burney P, Jarvis D, et al. Variation in bronchial responsiveness in the European Community Respiratory Health Survey (ECRHS). Eur Respir J 1997; 10: 2495-2501.

9 Grootendorst DC, Rabe KF. Mechanisms of bronchial hyperreactivity in asthma and chronic obstructive pulmonary disease. Proc Am Thorac Soc 2004; 1: 77-87.

10 Tønnesen P, Pisinger C, Hvidberg S, et al. Effects of smoking cessation and reduction in asthmatics. Nicotine Tob Res 2005; 7: 139-148.

11 Piccillo G, Caponnetto P, Barton S, et al. Changes in airway hyperresponsiveness following smoking cessation: comparisons between Mch and AMP. Respir Med 2008; 102: 256-265.

12 Van den Berge M, Vonk J, Gosman M, et al. Clinical and inflammatory determinants of bronchial hyperresponsiveness in COPD. Eur Respir J 2012; 40: 1098-1105.

13 Sovijärvi AR, Malmberg LP, Reinikainen K, et al. A rapid dosimetric method with controlled tidal breathing for histamine challenge. Repeatability and distribution of bronchial reactivity in a clinical material. Chest 1993; 104: 164-170.

14 Pallasaho P, Lundbäck B, Läspä SL, et al. Increasing prevalence of asthma but not of chronic bronchitis in Finland? Report from the FinEsS-Helsinki Study. Respir Med 1999; 93: 798-809.

15 Pallasaho P, Rönmark E, Haahtela T, et al. Degree and clinical relevance of sensitization to common allergens among adults: a population study in Helsinki, Finland. Clin Exp Allergy 2006; 36: 503-509.

16 Viljanen AA, Haltunen PK, Kreus KE, et al. Spirometric studies in non-smoking, healthy adults. Scan J Clin Lab Invest Suppl 1982; 159: 5-20.

17 Juusela M, Pallasaho P, Sarna S, et al. Bronchial hyperresponsiveness in an adult population in Helsinki: decreased FEV1, the main determinant. Clin Respir J 2013; 7: 34-44.

18 Cockroft C, Murdock K, Mink J. Determination of histamine PC20; comparison of linear and logarithmic interpolation. Chest 1983; 84: 505-506.

19 Standardization of spirometry, 1994 update. American Thoracic Society. Am J Respir Crit Care Med 1995; 152: $1107-1136$.

20 ATS/ERS recommendations for standardized procedures for the online and offline measurements of exhaled lower respiratory nitric oxide and nasal nitric oxide, 2005. Am J Respir Crit Care Med 2005; 171: 912-930.

21 Pride NB. Assessment of changes in airway calibre I. Tests of forced expiration. Br J Clin Pharmacol 1979; 8: 193-203.

22 Nadif R, Matran R, Maccario J, et al. Passive and active smoking and exhaled nitric oxide levels according to asthma and atopy in adults. Ann Allergy Asthma Immunol 2010; 104: 385-393.

23 Grönke L, Kanniess F, Holz $\mathrm{O}$, et al. The relationship between airway hyper-responsiveness, markers of inflammation and lung function depends on the duration of the asthmatic disease. Clin Exp Allergy 2002; 32: 57-63.

24 Rouhos A, Kainu A, Karjalainen J, et al. Atopic sensitization to common allergens without symptoms or signs of airway disorders does not increase exhaled nitric oxide. Clin Respir J 2008; 2: 141-148.

25 Kanner R, Connet J, Altose M, et al. Gender difference in airway hyperresponsiveness in smokers with mild COPD. The Lung Health Study. Am J Respir Crit Care Med 1994; 150: 956-961.

26 Prieto L, Lopez V, Llusar R, et al. Differences in the response to methacholine between the tidal breathing and dosimeter methods: influence of the dose of bronchoconstrictor agent delivered to the mouth. Chest 2008; 134: 699-703. 
27 Pellegrino R, Viegi G, Brusasco V, et al. Interpretative strategies for lung function tests. Eur Respir J 2005; 26: 948-968.

28 Kainu A, Lindqvist A, Sarna S, et al. FEV1 response to bronchodilation in an adult urban population. Chest 2008; 134: $387-393$.

29 Jansen DF, Timens W, Kraan J, et al. (A)symptomatic bronchial hyper-responsiveness and asthma. Respir Med 1997; 91: 121-134.

30 Scichilone N, Messina M, Battaglia S, et al. Airway hyperresponsiveness in the elderly: prevalence and clinical implications. Eur Respir J 2005; 25: 364-375.

31 Chaudhuri R, Livingston E, McMahon A, et al. Effects of smoking cessation on lung function and airway inflammation in smokers with asthma. Am J Respir Crit Care Med 2006; 174: 127-133.

32 Pallasaho P, Juusela M, Lindqvist A, et al. Allergic rhinoconjunctivitis doubles the risk for incident asthma - results from a population study in Helsinki, Finland. Respir Med 2011; 105: 1449-1456.

33 Willemse B, Postma D, Timens W, et al. The impact of smoking cessation on respiratory symptoms, lung function, airway hyperresponsiveness and inflammation. Eur Respir J 2004; 23: 464-476. 